\title{
As (re)configurações subjetivas e identitárias de negros na Universidade: Fricções epistêmicas e aquilombamento acadêmico
}

Subjective and identity (re)configurations of black people in the University: Epistemic frictions and academic marronage

\author{
João Paulo Siqueira \\ Rodrigo Maciel Ramos \\ Universidade de Brasília
}

\begin{abstract}
Resumo
Considerando uma perspectiva decolonial, em que as universidades atuam como instituições colonialistas, essas se mostram como um lócus fértil para pesquisar a vivência de sujeitos que fogem do ideal eurocêntrico. Este artigo analisa os processos de subjetivação, sofrimento e resistência que perpassam as trajetórias de quatro estudantes negros de graduação e pósgraduação da Universidade de Brasília, pertencentes a diferentes coletivos negros. A pesquisa se inspira na epistemologia qualitativa e no método construtivo-interpretativo, e enfatiza a relação colaborativa na produção de conhecimento. Nos encontros entre pesquisador e sujeitos de pesquisa foram realizadas duas entrevistas semiestruturadas que geraram os seguintes indicadores: (1) racialização (crítica), (2) choque e sofrimento ao entrar na Universidade, (3) aquilombamento acadêmico, e (4) negras epistemologias, os quais apontam para centralidade dos coletivos negros em suas trajetórias, mediando sofrimentos e fortalecimentos. Em comum, as fricções trouxeram (re)configurações subjetivas e o aquilombamento acadêmico foi sinônimo de sobrevivência e saúde mental.
\end{abstract}

Palavras-chave: Racismo; Subjetividade negra; Saúde mental; Aquilombamento acadêmico

\begin{abstract}
Decolonial perspectives understand that universities act as colonialist institutions, therefore those spaces are fertile locus for researching the experience of subjects who escape eurocentric ideal. This article analyzes the processes of subjectivity, suffering and resistance that permeate the trajectories of four black graduate and postgraduate students at the University of Brasilia, belonging to different black collectives. This research was inspired by qualitative epistemology and the constructive-interpretative method, and emphasizes the collaborative relationship in the production of knowledge. In the meetings between researcher and research subjects, two semi-structured interviews were carried out and they generated the following indicators: (1) racialization (critic), (2) shock and suffering when entering the University, (3) academic marronage, and (4) black epistemologies, which point to the centrality of black collectives in their trajectories, mediating suffering and strengthening. In common, the frictions brought subjective (re) configurations and academic marronage was synonymous with survival and mental health.
\end{abstract}

Keywords: Racism; Black subjectivity; Mental Health; Academic Marronage 


\section{INTRODUÇÃO}

Nas duas últimas décadas, as universidades públicas brasileiras foram marcadas por intensas transformações sociais impulsionadas pelas políticas de cotas. 0 ingresso de pessoas negras colocou em questão um sistema de ensino superior outrora pensado para a formação de uma elite branca (Carvalho, 2011; Lopes, 2011), gerando uma fricção epistêmica entre o conhecimento produzido e ensinado nas universidades e as demandas da maior parte da população brasileira, que é negra. Essa situação expôs o papel da universidade brasileira como uma instituição colonialista, aberta para receber e difundir teorias eurocentradas geradas nos distantes contextos dos países centrais, mas de costas para a realidade social de sua população e para as potencialidades de suas epistemes.

Sendo um território estratégico de disputa epistemológica, da luta antirracista e de ascensão de classe para pessoas negras, a Universidade tem se apresentado também como um caminho político de valorização da negritude e construção de uma sociedade igualitária (Castro e Mayorga, 2018).

Ao se observar a produção científica sobre a implementação de políticas de ações afirmativas, temos que essa é bastante vasta, e versa desde as consequências das cotas para as instituições, enquanto luta política, até as falhas na implementação das políticas, sob a lente de diversas áreas do conhecimento (Fontoura, 2019). uma menor produção acerca de reflexões sobre a permanência destes estudantes no ambiente universitário, a trajetória de estudantes negros e a fundação de coletivos negros (Oliveira et al., 2020).

0 presente artigo pretende contribuir com esse campo de estudos analisando, a partir das trajetórias subjetivas de quatro estudantes negros, o processo de inclusão de pessoas negras na Universidade de Brasília (UnB), o qual não é livre de resistência e nem de sofrimento do sujeito que se arrisca a ocupar espaços não pensados para ele. Assim, nesse contexto, os coletivos negros se apresentaram como lócus de racialização crítica e luta política antirracista, com consequente promoção na saúde.

Como forma de acessar a cultura acadêmica, na qual se desenvolvem essas trajetórias, seguimos o pensamento decolonial de Immanuel Wallerstein (2007) e propomos inicialmente uma análise histórica de longa duração dos processos estruturantes da Universidade enquanto uma instituição colonialista promotora da branquitude, para em seguida realizar a discussão sobre a trajetória desses estudantes por esse ethos. 


\section{Tradições acadêmicas no estudo das relações raciais}

Historicamente, muito foi pensado a respeito das diferenças comportamentais e psicológicas entre os povos. 0 evolucionismo social, proposto por Herbert Spencer no século XIX, mostrou-se como uma das tradições nas discussões raciais do século passado, em que se realizava uma extrapolação das concepções darwinianas para vida social, defendendo a existência de um determinismo biológico, em que os humanos nascem com determinadas habilidades de acordo com sua "raça", sendo que as características brancas eram consideradas superiores às demais (Laraia, 2005; Tempesta et al., 2019). No cenário brasileiro, esse pensamento influencia Nina Rodrigues, a teorizar que o que conceitua como primitivismo da cultura afro-brasileira é decorrente da inferioridade genética do negro (Santos et al., 2012).

Em oposição a essa concepção, o antropólogo Franz Boas cumpriu uma quebra paradigmática nos estudos sobre raças ao argumentar que não há evidências científicas que expliquem uma hierarquia natural entre as raças, além de ressaltar a sobreposição da influência cultural perante a biológica. Defendendo, também, que a raça se refere apenas aos traços físicos enquanto que o funcionamento psíquico e moral é determinado pela cultura (Boas, 2004). Essa discussão emergente até meados do século XX, foi desenvolvida no Brasil nas produções de Gilberto Freyre e Donald Pierson.

A principal tese defendida por Freyre era de que não havia racismo no Brasil, e que brancos e negros viviam em igualdade e harmonia (Freyre, 2003). Pierson em sua obra Brancos e pretos na Bahia (1971) versa sobre a sociedade multirracial de classes, valoriza a possibilidade de ascensão social de pretos e pardos, e ignora a existência do racismo. Em sua concepção, a segregação social era devida mais às condições socioeconômicas dos indivíduos do que pela cor da pele.

$\mathrm{Na}$ segunda metade do século XX, de forma a se opor aos defensores da ideologia da suposta igualdade racial no Brasil, Abdias do Nascimento (1978/2016) e Lélia Gonzalez (1988) derrubam a noção de democracia racial existente nos estudos sobre relações raciais no Brasil, e as denunciam como sendo um fenômeno de caráter vertical, no qual brancos tem a hegemonia social assegurada sobre pessoas negras a partir de diversos mecanismos institucionalizados na sociedade. Nascimento (1978/2016) expõe a falsa ideia de democracia racial defendida por Freyre, denunciando-a como uma estratégia de promover o apagamento das identidades negras e embranquecimento cultural e fenotípico da população negra no Brasil.

Em paralelo, durante esse período são desenvolvidos estudos em psicologia social por Virgínia Bicudo, Aniela Ginsberg e Dante Moreira Leite, em que as dife- 
renças entre raças no Brasil explicadas pela inferioridade genética são deslocadas para o foco das desigualdades sociais. E a partir dos anos 90 , os psicólogos sociais Jurandir Freire Costa, Iray Carone, Cida Bento e Edith Pizza, se apropriam das discussões sobre branquitude, invertem o lócus de investigação dos estudos sobre raça no Brasil, e a produção acadêmica eurocentrada e o comportamento do branco passam a ser objeto de análise na construção da noção de raça (Santos et al., 2012).

A socióloga Gonzalez (1988), uma das referências no que tange ao pensamento negro contemporâneo, traz a termo a estreita relação entre racismo e colonização, não só o racismo enquanto uma criação colonial, mas também como o tipo de colonização imposta influenciou a forma como o racismo se dá no contexto pós-colonial nas Américas. Ela argumenta que, enquanto nos EUA a separação entre raças é radical, no Brasil a tecnologia de discriminação racial é mascarada, a qual ela nomeou de racismo por denegação, e já havia sido desenvolvida em tempos anteriores na península ibérica.

De forma que, apoiados nas teorizações de Gonzalez e de autores da perspectiva decolonial (Bernardino-Costa et al., 2019; Wallerstein, 2007), enxergamos a relação direta entre colonização e racismo como dimensão fulcral na constituição do sistema-mundo moderno/colonial e do capitalismo. Uma vez que a expansão econômica e de tecnologia do mundo eurocêntrico que se iniciou com a invasão territorial das Américas e se estendeu por toda a orbe terrestre exerce influência até os dias de hoje. Atuando desde uma polarização em que $80 \%$ dos países são dominados em termos políticos, sociais e econômicos pelos outros $20 \%$, e assim uma maioria subalterna não-ocidental é quem sustenta a situação privilegiada dos países ocidentais, brancos, desenvolvidos.

Após séculos, as Américas, incluso o Brasil, ainda carregam diversos sintomas similares decorrentes do colonialismo, dentre os quais destaca-se a desigualdade estrutural entre brancos e não-brancos, o que nomeamos de racismo. Nestes contextos, os traços fenotípicos associados à população negra ou indígena determina, de forma significativa, a experiência subjetiva e material desses indivíduos na realidade social (Grosfoguel, 2016).

A colonização não teve fim após a independência dos países, mas apresenta uma continuidade dessa dinâmica de poder, agora como colonialidade. Ao teorizar a colonização enquanto um fato social total, como proposto por Georges Balandier (1993), podemos enxergá-la como um sistema que estruturou e estrutura todas as esferas da sociedade, como a política, educação, economia, religião e também nas questões ligadas às subjetividades. Ainda de acordo com Balandier (1993), a imposição desse sistema se deu/dá a partir das instituições colonialistas, as quais, de maneira normatizadora, introjetam os preceitos dos 
países centrais na realidade social pós-colonial, como é o caso da idealização de uma suposta supremacia das etnias europeias diante das demais. Nesse sentido, dentre as instituições colonialistas, destacamos as Universidades enquanto instituições da colonialidade do ser/saber, sobretudo no seu papel de exercer a homogeneização e universalização eurocentrada dos saberes transmitidos (Carvalho, 2011; 2019; Carvalho et al. 2020).

\section{Universidades e a colonialidade}

As universidades, historicamente, atuaram enquanto instituições coloniais com poder de determinar quais conhecimentos seriam válidos e legítimos, havendo uma valorização dos conhecimentos científicos oriundos da Europa, de uma população branca, como sendo os verdadeiros saberes e uma desqualificação de epistemologias de povos originários e étnicos, os povos não-brancos, como saberes primitivos e folclóricos (Ballestrin, 2013; Dussel, 1993; Mbembe, 2013; Mignolo, 2003; Rivera, 2010; Quijano, 1992).

Além disso, as epistemologias ensinadas nos espaços acadêmicos de todo o mundo partem de experiências culturais vividas no Norte global e mesmo assim são utilizadas para explicar a realidade social do Sul global, não havendo nenhum recorte contextual, em uma lógica que Raewyn Connell (2012) chama de metrocentrismo.

Na Austrália ou no Brasil, nós não citamos Foucault, Bourdieu, Giddens, Beck, Habermas etc. porque eles conhecem algo mais profundo e poderoso sobre nossas sociedades. Eles não sabem nada sobre nossas sociedades. Nós os citamos repetidas vezes porque suas ideias e abordagens tornaram-se os paradigmas mais importantes nas instituições de conhecimento da metrópole - e porque nossas instituições de conhecimento são estruturadas para receber instruções da metrópole. (Connell, 2012, p. 10)

O contexto social em que ocorreu a inclusão das universidades em território brasileiro apresenta uma face nefasta. Sendo abertamente defendida pela elite republicana como um elemento fundamental em um projeto de modernização e industrialização da sociedade brasileira no início do século XX, apresentava-se que o propósito dessas universidades seria de preparar uma elite intelectual para ocupar os cargos de liderança em um Brasil "novo e moderno" (Carvalho, 2011; Carvalho et al., 2020).

Esse mesmo discurso, delegava o atraso da sociedade brasileira em relação às modernas sociedades europeias, à massiva presença de negros, tidos naquele período, por uma abordagem científica eugênica, como uma raça atrasada em relação às etnias brancas. $E$, assim, para a elite republicana outra forma de modernizar o Brasil era estimular a imigração de populações brancas, com doa- 
ção de terras e oferta de empregos, promovendo o embranquecimento cultural e fenotípico da população. Ficando evidente que a entrada das universidades no Brasil não foi pensada para as populações nativas ou negras, mas estruturada por e para brancos.

\section{Panorama da realidade racial na Universidade de Brasília}

Segundo José Jorge de Carvalho et al. (2020), as instituições universitárias brasileiras atuam de forma desterritorializada, e adotam uma prática monoespistêmica, eurocentrada, de transmissão e produção do conhecimento. Assim, segundo o autor que é uma das referências na proposição de um modelo de Universidade brasileira, não importa a localização territorial da Universidade, já que salvo algumas exceções elas atuam de forma uniforme com o propósito de preparar mão de obra qualificada e desenvolver tecnologias para expansão capitalista.

A escolha pela UnB como foco de estudo se deve ao fato de que ela foi pioneira em propor (Carvalho e Segato, 2002) e adotar um sistema de cotas para ingresso de pessoas negras na graduação. Em 2003, ano em que se inicia a entrada por cotas dos estudantes negros, a porcentagem de estudantes negros na UnB estava de acordo com a média nacional (Carvalho, 2005). Posteriormente, em 2012, através da Lei $n^{\circ} 12.711 / 2012$, a UnB e as demais instituições federais de ensino superior passaram a reservar, de forma progressiva, $50 \%$ do quantitativo de vagas para alunos oriundos de escolas públicas, sendo que metade dessa reserva deveria ser restrita a pessoas pretas, pardas e indígenas. E assim, passados 15 anos da adoção dessas políticas de inclusão social, a quantidade de estudantes negros - pretos e pardos - corresponde a $47 \%$ do total de discentes da universidade, enquanto que a quantidade de brancos corresponde a $40 \%$ (Universidade de Brasília, 2019).

Estes dados confirmam a eficácia das políticas de ações afirmativas, sendo visível na UnB uma maior presença negra, embora ainda seja controverso se realmente pessoas com a tonalidade de cor preta ou parda, como afirma o estudo, sejam maioria. 0 que poderia evidenciar, também, alguma falha na forma como ocorrem os processos seletivos no sistema de cotas na graduação, que se baseia apenas na autodeclaração racial do candidato.

Ainda sobre esse tema, Carvalho (2019) argumenta que o ingresso das populações negras e indígenas na Universidade não representou uma revisão epistemológica dos saberes ensinados nos ambientes acadêmicos. A não inclusão dos saberes ancestrais e de saberes ancorados nas experiências de vida das populações não brancas dentro das grades curriculares acaba por gerar uma continui- 
dade do intento inicial do papel atribuído às Universidades de embranquecimento da sociedade brasileira dentro de um projeto de modernização.

Assim, é de se esperar que a partir da fricção entre as epistemologias propagadas pelas Universidades e as epistemologias provenientes das realidades sociais de pessoas negras que ingressaram nessas instituições, ocorram (re)configurações subjetivas e identitárias dos discentes negros, geradas pela necessidade de se adotar estratégias de sobrevivência em um ambiente que não foi pensado para a existência de pessoas não brancas. Essa afirmação está em conformidade com o que foi identificado por diversos autores que se dedicaram a investigar trajetórias de estudantes negros universitários (Araújo et al., 2020), e cujos estudos apontam que invariavelmente todos tiveram a experiência de racismo, isso em diversas localidades do Brasil, independente da renda familiar, de ser portador ou não de deficiência, ser brasileiro ou estrangeiro, do curso que frequentavam, da orientação sexual e do gênero. No entanto, embora a experiência como acadêmico negro esteja associada à violência e ao sofrimento, também de forma comum, o espaço acadêmico é representado como meio para ascensão social e produção de conhecimento antirracista.

Uma dessas estratégias, aprofundada nesse artigo, parece estar relacionada a necessidade de aderir a algum grupo social voltado para ações de afirmação identitária. Em janeiro de 2021 existiam cerca de 16 organizações, coletivos, grupos de pesquisa ou laboratórios dedicados à articulação política da comunidade negra na UnB, segundo dados coletados no site do Centro de Convivência Negra. A quantidade significativa dessas associações políticas, obviamente relacionadas ao aumento do número de estudantes negros nos últimos 20 anos, parece estar diretamente ligada a necessidade de um movimento de resistência e fortalecimento da identidade e subjetividade negra no contexto acadêmico.

\section{MÉTOdo}

Inspiramo-nos na epistemologia qualitativa e no método construtivointerpretativo (González Rey e Mitjáns Martínez, 2017) como forma de produção de conhecimento. Tendo em vista que esse enfatiza a relação colaborativa e política na produção do conhecimento. Nesta perspectiva, o caráter dialógico de produção dos conhecimentos se evidencia no encontro entre as subjetividades do pesquisador e do sujeito participante da pesquisa, pois esse se dá de forma ativa, e se assume que o participante da pesquisa tem interesse em refletir sobre suas realidades sociais, muitas vezes sobre temas que não havia refletido antes. 
Na proposta teórica de Fernando González Rey e Albertina Mitjáns (2017), a subjetividade é entendida como a capacidade de agenciamento do indivíduo, de estabelecer relações dialéticas com a cultura, de atribuir significados as suas experiências de vida, e de se relacionar com o espaço social na forma como ele está configurado. Nesse sentido, a cultura não é entendida como uma entidade separada do sujeito, mas o sujeito faz parte da cultura, sendo seu agente de transformação, bem como é transformada por ela. Em atendimento a essa perspectiva é que se buscou nesse artigo, primeiramente, apresentar como está configurada a cultura acadêmica para em seguida analisar as trajetórias subjetivas dos estudantes negros que se desenvolvem nesse espaço, que incluem experiências de sofrimento, processos de resistência e subjetivação gerados em contato com os aquilombamentos.

Uma vez que a subjetividade não pode ser acessada de forma direta senão pela emergência de indicadores de sentidos subjetivos gerados pelas configurações subjetivas do indivíduo. A trajetória investigativa foi marcada pela produção de indicadores atribuídos aos sentidos subjetivos gerados durante a interação entre pesquisador e sujeito de pesquisa. Nesse sentido, os indicadores atuam como um conjunto de elementos cujos significados são convergentes entre si e permitem a produção de hipóteses que podem ou não ser confirmadas, e que ao serem retornadas ao sujeito permitem estimular a produção subjetiva do participante de forma a integrar o modelo teórico da pesquisa (González Rey e Mitjáns, 2017).

A interação entre pesquisador e participantes, se deu através da realização de dinâmicas conversacionais, em plataforma digital. Cada participante participou de dois encontros, gravados, sendo que os primeiros ocorreram entre 03/09 e 14/09/2021 e tiveram a duração aproximada de 60 minutos. Nesse primeiro momento o pesquisador e cada um dos sujeitos participantes deveriam, enquanto agentes, refletir sobre os seguintes eixos norteadores gerados pela revisão de literatura e pela composição do cenário social de pesquisa: (1) contextualização do participante antes de ingressar na Universidade, buscando informações tanto sobre a origem e trajetória educacional quanto a aspectos de racialidade; (2) o contato com as discussões políticas antirracistas; (3) a vivência nos primeiros semestres de UnB; (4) as motivações e a importância de se associarem aos coletivos negros e, por fim; (5) a percepção sobre os conhecimentos transmitidos pela UnB.

A intenção da primeira dinâmica conversacional era, além de obter informações sobre a trajetória subjetiva do participante, acessar os sentidos subjetivos gerados nas suas expressões relacionadas aos temas abordados e produzir indicadores de novas produções de sentido. As gravações serviram também para 
em uma posterior análise elaborar novos indicadores que seriam abordados em um segundo momento.

Entre 07/12 e 09/12 foi realizada a segunda sessão de dinâmicas conversacionais, nessas, os indicadores de sentidos subjetivos construídos nas/ a partir das dinâmicas conversacionais foram apresentados aos sujeitos de pesquisa, permitindo assim a produção de novas expressões subjetivas, bem como enriquecimento, confirmação ou negação da teorização elaborada a partir de seus discursos. A duração dessas dinâmicas foi de 26 a 45 minutos.

Tendo como critério de inclusão (1) ser um(a) estudante da UnB auto identificado(a) como pessoa negra e (2) estar vinculado a algum coletivo negro dessa universidade. Selecionamos quatro estudantes, a escolha dos participantes se deu pelo protagonismo performado dentro dos coletivos, bem como pela facilidade para entrar em contato, tendo em vista que são pessoas conhecidas pelo entrevistador, com quem compartilharam vivências em coletivos e atividades exceto Rodrigo que foi indicação de uma colega pesquisadora.

Foram entrevistados dois homens e duas mulheres, entre 20 e 27 anos, em diferentes níveis de formação, Luana na graduação em Artes Cênicas, Bianca no mestrado em Psicologia, Vinícius no doutorado em Antropologia e Rodrigo doutorando em Direito. O ano de ingresso na UnB variou entre 2013 e 2017, ou seja, todos têm uma trajetória temporal significativa.

No início das dinâmicas, foi apresentado o TCLE aos participantes e informado que poderiam sair da pesquisa quando desejassem. Em acordo com os participantes, não foram alterados os seus nomes nem os cursos que frequentam, pois eles entendem que a participação nessa pesquisa representa uma ação identitária afirmativa.

\section{RESULTAdOS/DISCUSSÃo}

Os indicadores da subjetividade gerados pela interação entre pesquisador e sujeitos de pesquisa foram agrupados nas seguintes categorias de análise: (1) racialização (crítica), (2) choque e sofrimento ao entrar na Universidade, (3) aquilombamento acadêmico, e (4) negras epistemologias.

\section{Racialização (crítica)}

A primeira categoria de análise foi construída ao agrupar os indicadores subjetivos gerados a partir dos discursos dos entrevistados, estando relacionados aos seus processos de racialização, ou seja, a atribuição de pertença racial realizada pelos outros (Guimarães, 2003; 2016). Alguns aspectos na trajetória de vida se mostraram como centrais para que os sujeitos pudessem ser demarcados en- 
quanto negros, tais como questões estéticas, sobretudo relacionadas ao corpo e a vivência interracial dentro da própria família.

Em conformidade com o pensamento de Achille Mbembe (2014), a dimensão da racialização se apresentou como um processo imposto, em que os sujeitos não tinham consciência do que significava ser negro, apenas experenciavam o racismo, como está indicado no discurso de Bianca (entrevista pessoal, setembro de 2020): "racialização vem desde sempre, através do corpo [...] sabia que era negra e sofria por isso, mas não sabia o porquê e o que motivava essa violência racial nas outras pessoas". Esse trecho de seu discurso demonstra que uma das consequências da racialização acrítica, resultante da forma como a sociedade está configurada, é de levar o sujeito negro a sentir-se culpado pelos problemas gerados pelo racismo.

Como afirma Valeska Zanello (2018), os processos de subjetivação são mediados pela cultura e, em nosso caso, uma cultura racista e misógina. Dessa forma, tornar-se pessoa é ser designado como branco ou negro, homem ou mulher. Sendo dado às pessoas brancas, principalmente os homens, caminhos privilegiados de subjetivação, em que somada a branquitude (Schucman, 2012) aos brancos é concedido, e reafirmado pelos dispositivos, o lugar de referência ideal, representantes da intelectualidade, educação e da beleza, enquanto aos negros é dado o seu oposto, ou seja, a referência do indesejado (Souza, 1983).

No Brasil, o racismo se dá de forma disfarçada e a marcação de seus alvos acontece através de traços fenotípicos, como a cor da pele e o cabelo (Gonzalez, 1988; Nogueira, 2007). Esse fato surge em indicadores elaborados pelo discurso de Bianca ao relatar que, antes de realizar uma racialização crítica, desde muito nova, uma das formas de fugir dessa violência simbólica era mascarando seus traços negros, por exemplo submetendo seus cabelos a químicas e máquinas para alisá-los: "Sofri muito bullying na escola e passei a alisar o cabelo, então foram várias conformações do meu corpo para estar ali no ambiente da branquitude" (Bianca, entrevista pessoal, setembro de 2020).

De forma coincidente, todos os participantes relataram pertencer a núcleos familiares interraciais. 0 contexto familiar é o primeiro ambiente no processo de tornar-se pessoa, e a partir do qual é possível tanto afirmar a racialidade quanto negá-la, e segundo Lia Vainer Schucman, Belinda Mandelbaum e Luis Fachim (2017) isso se torna ainda mais evidente em famílias interraciais. De forma complementar essa questão, para Frantz Fanon (1952/2008) a compreensão da racialidade é relacional, o tornar-se negro ocorre muitas vezes na mediação realizada pela interação com o outro, que é branco, inclusive em sua própria casa. Como aponta Vinicius (entrevista pessoal, setembro de 2020), ao relatar suas vivências: "Desde muito novo esse apontamento racial já me era 
muito forte, porque sempre que falavam de beleza, meu irmão que era bonito e coisas desse tipo". De forma que os indicadores construídos evidenciam que as dinâmicas familiares contribuem para o processo de racialização negra, o que está em acordo com o que Neusa Santos Souza (1983) expõe sobre esse processo não acontecer somente pela diferenciação com os brancos, mas também como uma imposição sistemática do arquétipo branco como o Ideal de Ego.

Se por um lado o processo de imposição social da racialidade acontece de forma passiva (Mbembe, 2014), a percepção crítica a respeito do racismo acontece pela agência dos sujeitos, sobretudo mediada por ambientes e relações sociais que pautam as desigualdades sociais. No caso dos participantes, a universidade foi o contexto declarado em que todos eles desenvolveram o que chamamos de racialidade crítica, havendo uma similaridade desse termo com a forma autogerada como Antônio Sérgio Guimarães (2016) usa a categoria raça, entendida nessa pesquisa como passar a assumir o pertencimento racial como uma reivindicação política, ter consciência do racismo e suas consequências, de entender o porquê de algumas violências vividas. Todavia, a fim de não universalizar a experiência dos negros na universidade, o relato de pesquisa feita por Ricardo Castro e Cláudia Mayorga (2018), na UFMG com negros de classe média, nos mostra a existência de diferentes necessidades e percepções a depender da classe social.

O indicador construído a partir da convergência dos sujeitos participantes sobre a percepção da racialidade crítica como sendo um processo adquirido nas vivências entre pares dentro da universidade também surge no discurso de Rodrigo (entrevista pessoal, setembro de 2020) ao se expressar sobre a necessidade de adquirir uma fundamentação política e social de enfrentamento direto às violências: "tornar-se negro criticamente esteve muito relacionado com o tornar-se militante". Nesse sentido, Stephanie Lima (2020) aponta que a universidade é um ambiente muito fértil para o desenvolvimento de uma postura questionadora diante das desigualdades sociais, uma vez que os sujeitos alvos de preconceito encontram possibilidades de produzir e elaborar formas de enfrentamento, seja através de pesquisas científicas ou ação direta, especialmente ao encontrar pessoas com as mesmas demandas de sofrimento social. Para além das questões "individuais", cabe ressaltar a importância do espaço universitário como reivindicação política para os grupos sociais subalternizados, haja vista que além de ser um direito, é tido como uma das maiores possibilidades de ascensão social e autonomia (Lima, 2020).

A simples introdução de uma pessoa negra ao lócus universitário como foi historicamente configurado - sem políticas efetivas de permanência - é uma expe- 
riência geradora de sofrimento, a qual pode ser atenuado por saber qual é a origem da separação historicamente constituída na sociedade brasileira entre locais pertencentes às pessoas negras e aos locais reservados para pessoas brancas, como é bem exemplificado no discurso de Luana (entrevista pessoal, setembro de 2020): "as coisas simplesmente ainda doem, mas não doem tanto, porque agora eu sei do porquê das violências", sendo fundamental pontuar que essa reconfiguração subjetiva é um processo que não acontece de forma linear e muito menos pacífica. Ademais, Cláudia Mayorga e Luciana Maria Souza (2012) pontuam que a implementação de políticas de permanência também deve possibilitar a reflexão crítica em relação às desigualdades sociais, para que assim os sujeitos subalternizados possam ressignificar suas histórias e transformar a realidade.

De modo geral, entrar na universidade simbolizou uma grande conquista, tanto pessoal quanto familiar. Porém, o ingresso nesse novo universo também trouxe impactos negativos à subjetividade, sobretudo no que se refere ao abalo da autoeficácia como definido por Albert Bandura (1997). O que de certa forma é sintomático, visto que em toda trajetória subjetiva anterior à entrada na universidade sempre foram reconhecidos enquanto potências intelectuais. As expressões subjetivas extraídas dos discursos dos participantes referentes a essas vivências nos levaram a um outro agrupamento de indicadores.

\section{Choque e sofrimento ao entrar na Universidade}

Em relação a essas vivências, os seguintes trechos do discurso de Luana demonstram que a experiência de inserção na UnB, no curso de Artes Cênicas, trouxe impactos negativos em sua subjetividade, mesmo que anteriormente nos locais em que geralmente frequentava como escola, família e vizinhança, composto em sua maioria por pessoas negras, ela se sentisse uma pessoa bastante segura de si mesma e de suas potencialidades.

Quando eu entrei na universidade, foi um grande susto, porque eu nunca tinha visto tantas pessoas brancas num só ambiente, um curso extremamente branco. 0 departamento tinha apenas dois professores negros, o que era muito em relação aos outros departamentos. [...] começaram as autossabotagens. Sempre fui muito corajosa, nunca tive medo do mundo por não conhecer os riscos. Quando entrei e vi o tanto de pessoas brancas, percebi melhor a questão racial, então foram muitas autossabotagens, medo de produzir. Em vários momentos não era chamada para participar de projetos e eram sempre o mesmo tipo de pessoa que eram convidadas, garotas de escolas privadas de elite. Então vem muito forte a autossabotagem, de ter medo [...] passei com nota alta no processo seletivo, mas quando entrei veio todo o medo. (Luana, entrevista pessoal, setembro de 2020) 
Segundo ela, os primeiros semestres foram difíceis devido à falta de identificação, o que se materializou nas atitudes e comportamentos, como no sentimento de inferioridade, no medo de aparecer e se posicionar, bem como nas questões afetivas, de desamparo. Experiência essa que também foi vivida por Bianca.

Sentia uma solidão que parecia incontornável, eu convivia e tal com colegas brancos, conversava, fazia trabalho e tudo mais, mas eu não tinha nenhuma afinidade de trocar coisas íntimas, de o que estava sendo aquela experiência. Enquanto que os brancos estavam sempre entre amigos. (Bianca, entrevista pessoal, setembro de 2020)

Assim, a partir das experiências de ingresso na UnB, aos indicadores de autossabotagem e solidão, é possível se somar mais um indicador de como o ambiente acadêmico se mostrou adoecedor para pessoas negras ao promover a sua desqualificação. Como expresso por Vinicius que descreve que além de ter passado pela experiência de questionar as próprias habilidades, passou, na seleção para o mestrado, por experiências de desvalorização, em que se evidencia a dimensão racista estruturada na sociedade e espelhada nos ambientes acadêmicos, tanto ao sentir uma não apreciação de suas contribuições em sala, quanto a hipervalorização de contribuições similares dos colegas brancos, e no não reconhecimento das suas conquistas.

Numa seleção com menos candidatos que o usual, a banca desclassificou $2 / 3$ das candidatas logo de cara na fase do ensaio. Eu fui aprovado em terceiro lugar, mas comecei a ouvir que eu só tinha sido aprovado porque minha orientadora estava na banca e que ela tinha lido meu ensaio antes. Foi uma experiência muito violenta, por muito tempo eu não consegui ficar feliz como o momento merecia porque por muito tempo não me achava digno de ocupar aquela vaga. Depois eu fui comparar meu currículo com o dos colegas, obviamente que o currículo não diz muito coisa, mas o meu era se não o melhor, era um dos dois melhores da turma. E fiquei pensando 'por que comigo tem esse tipo de acusação?' O mesmo acontece com outros colegas que vêm de família acadêmica ou que os orientadores estão na banca? (Vinícius, entrevista pessoal, setembro de 2020).

Após essas vivências, Vinícius diz ter percebido que há uma assimetria entre a valorização entre sujeitos brancos e negros na academia, que para ser reconhecido como potência não poderia apenas se equiparar aos brancos, mas trabalhar duas vezes mais, essa percepção dialoga diretamente com a noção de branquitude exposto por Lia Vainer Schucman (2012).

A situação descrita por Vinícius pode ser tomada como um indicativo de como o racismo impacta diretamente a saúde mental, visto que o sistema racista demanda muito mais dos estudantes negros, os quais já são alvo de violências es- 
truturais (Tavares e Kuratani, 2019). Marizete Damasceno e Valeska Zanello (2018) pontuam que a condição constante do racismo causa o desenvolvimento de transtornos, desde a ordem física à mental. Segundo João Luiz Bastos et al. (2014), no Brasil, há maior prevalência de Transtornos Mentais Comuns (TMC) entre a população negra do que entre as pessoas brancas. Esses dados, juntamente com os relatos de sofrimento psíquico de negros no contexto universitário, apontam para a necessidade de racialização do sofrimento, principalmente para psicologia, área a qual tradicionalmente tem se debruçado sobre aspectos relativos à saúde mental (Schucman e Gonçalves, 2020).

\section{Aquilombamento acadêmico}

Embora a vivência universitária seja marcada por essas questões em seu início, todos entrevistados experienciaram uma estratégia tradicional de sobrevivência da população negra para enfrentar a realidade racista: o aquilombamento, que é ressignificado na contemporaneidade, como sendo uma "reunião fraterna e livre, solidariedade, convivência, comunhão existencial" (Nascimento, 1980/2020, p. 263).

As expressões subjetivas dos participantes da pesquisa possibilitaram a geração de indicadores e a construção dessa categoria de análise, mostrando que o aquilombamento acadêmico é configurado a partir dos coletivos negros e atua também como uma tecnologia de promoção de saúde. Sendo isso observado pelo relato de aquisição de recursos subjetivos que permitiram aos participantes da pesquisa se reposicionar como sujeitos ativos dentro de uma sociedade estruturalmente racista e por ser um local de acolhimento afetivo a pessoas negras dentro da universidade. Luana relata um pouco dessa busca e sua respectiva importância:

Quando eu entrei na UnB, busquei me aproximar de pessoas parecidas comigo, foi um processo natural de identificação. 0 quilombo UnB era um espaço muito importante de acolhimento e afeto. Estar com pessoas negras mostra que você não está só, é uma rede de apoio e de bem estar. (Luana, entrevista pessoal, setembro de 2020)

Esse trecho de seu discurso dialoga diretamente com um trecho do discurso de Bianca, que exemplifica como, a partir do aquilombamento acadêmico, foram gerados recursos subjetivos que produziram o fortalecimento da autoeficácia, levando-a até mesmo a desejar a entrada em um mestrado.

Estar vinculado a um coletivo é fundamental para a sobrevivência afetiva. Na sala de aula, somos muito "não vistos", as nossas falas não são muito levadas a sério. Eu vejo que minha forma de me colocar, antes eu evitava falar em sala, eu tinha muito medo de ter minha fala desconsiderada. A 
partir da vivência com pessoas negras, pude me perceber uma pessoa falante e que tava tudo bem, talvez eu pudesse me importar menos com a receptividade da branquitude, e só dizer o que era importante pra mim, talvez ressoasse nas outras pessoas negras da turma, isso bastava para me sentir bem em falar. (Bianca, entrevista pessoal, setembro de 2020)

A partir da percepção de Marco Prado (2002), sobre a existência de uma relação entre mobilização social, identidades coletivas e processos de mudança, 0 sistema de cotas ao facilitar a presença massiva de negros na UnB permite a organização coletiva de estudantes negros em aquilombamentos que agem em prol da reinvidicação igualitária dos corpos negros e dos saberes negros no meio universitário. Assim, o sentimento de pertencimento a um grupo político identitário se torna um elemento potencializador de suas subjetividades.

Rodrigo, já inserido no âmbito da pós-graduação, aponta que os coletivos negros propiciaram o fortalecimento de sua pesquisa e de seu papel como pesquisador através da articulação em coletivos negros:

Muito importante para afirmar o lugar de pesquisador, afirmar minha pesquisa... a pesquisa se torna mais forte por causa do esforço coletivo, de não só ler e estudar coletivamente, mas de colocar meu texto em discussão com meus pares, com meus colegas que entendiam minhas demandas e referenciais. (Rodrigo, entrevista pessoal, setembro de 2020)

Entretanto, embora o coletivo aconteça em ambiente universitário, os ganhos subjetivos não se limitam ao universo acadêmico, Vinícius é categórico ao afirmar que os ganhos do aquilombamento se dão nas dimensões política, intelectual e também afetiva. Isso é mais evidente na trajetória de Rodrigo, que é oriundo de um estado distante e veio estudar em Brasília.

Ter um grupo que nos reconheça como pesquisador é importante. Isso atravessa também o afeto, extrapola a dimensão profissional. É um grupo de carinho, apoio e suporte. A maioria não é de Brasília. Então tem isso da perda do lugar de segurança, que é a casa e a família, então acabamos projetando aquilo nos lugares de maior aconchego, isso foi muito importante. Foi um espaço para desaguar. Compartilhar angústias e fortalecimento pessoal, de reestabilização. (Rodrigo, entrevista pessoal, setembro de 2020)

Entende-se, portanto, que o aquilombamento acadêmico se mostrou como uma tecnologia de cuidado em saúde mental para os negros na universidade, no sentido de promover saúde e proporcionar recursos para lidar com o contexto adoecedor. Tal como os quilombos, que tradicionalmente funcionam como operador terapêutico para a população afro-brasileira (Nascimento, 1980/2020).

Isto posto, porém, Bianca enfatiza a necessidade de não romantizar a formação de coletivos negros, sobretudo no que tange à essencialização dos negros en- 
quanto população estática e uniforme, que a identificação subjetiva ocurre apenas pelo pertencimento racial:

Poder dentro da própria negritude explorar a diversidade de pontos de vista [...] existe uma idealização nossa, enquanto pessoas negras, que no momento em que chegarmos no coletivo negro todas as nossas inquietações serão resolvidas, acolhidas e as vezes não. Existem os negros que são stalinistas, maoístas, os panafricanistas, anarconegros, etc. Muito importante esse espaço negro também como exploração de possibilidades de ser várias coisas, inclusive coisas que não concordamos entre nós. Isso é o que a branquitude não dá chance, nós temos que ser o negro negrólogo que impede o branco de cometer racismo, essa é a nossa função no grupo branco. Já no grupo negro, temos mais liberdade de ser outras coisas. (Bianca, entrevista pessoal, setembro de 2020)

Ainda inserido na lógica de não homogeneizar a vivência dentro dos coletivos negros, é importante acrescentar que as pessoas possuem outras identidades para além da negritude, como aspectos de gênero, classe e sexualidade, que são marcadores sociais da diferença/desigualdade que produzem sofrimento e estruturam os processos de subjetivação (Hall, 2006). Assim, nos parece sintomático que apenas as mulheres elencaram questões sobre as vivências afetivosexuais nas entrevistas pois, como afirma Zanello (2018), as questões afetivas e amorosas são identitárias para as mulheres, havendo diferentes implicações quando se intersecciona com raça/cor, como a questão do preterimento afetivo (Pereira, 2019). O que pode levar a um outro indicador não analisado nesse estudo, sobre como apesar dos coletivos negros serem locais de promoção de saúde a partir da geração de recursos subjetivos para lidar com o racismo, a discussão sobre masculinidade, tema tabu na sociedade como um todo, também não é explorado dentro dos coletivos negros, e assim permanece como um elemento adoecedor que vitimiza tantos homens quanto mulheres.

\section{Negras epistemologias}

Já no que tange à dimensão epistemológica, foram agrupados nessa categoria analítica os indicadores de sentidos subjetivos que remetem à percepção dos entrevistados sobre os conhecimentos promovidos pela universidade. De forma unânime, há a percepção de que a UnB, por ser ocidentalizada, não viabiliza diretamente conhecimentos referentes ao racismo e às relações raciais. $\mathrm{E}$ diante dessa falta, cabe aos coletivos negros e aos sujeitos associados pautarem as negras epistemologias, seja na sala de aula ou no ambiente do coletivo. Sendo assim, o aquilombamento acadêmico acaba por promover um enriquecimento intelectual de seus participantes e do ambiente universitário, promovendo conhecimentos que dialogam com a vivência da população negra. 
Bianca e Luana relatam que a busca por essas negras epistemologias é um processo solitário de peregrinação pelos departamentos da UnB. Os departamentos de filosofia e de sociologia são considerados os principais referenciais para os estudantes que realizam essa busca, pois são conhecidos como ambientes férteis para as discussões que são geradas justamente pelos docentes negros que estudam o racismo.

Para Vinícius e Rodrigo, a peregrinação em busca de conhecimentos negros se mostra como um "esforço duplo" a ser feito pelos sujeitos acadêmicos negros em seu processo de construção da racialidade crítica, visto que além de realizar essa busca por saberes que deem conta de suas vivências, terão que cumprir e se apropriar dos saberes clássicos de seus cursos que partem de uma matriz eurocêntrica. Ainda assim, Rodrigo não descarta esses conhecimentos, mas justifica a necessidade de se apropriar dos mesmos:

O conhecimento universitário é útil, é uma negociação que fazemos, não estamos batendo pestana à toa. Estamos... pois... acreditamos numa ascensão social e de poder que a educação permite, mas também, em alguma medida, temos a compreensão de que esse saber é limitado, justamente pela gênese que é violenta. [...] Isso gera mais necessidade de domínio sobre o conhecimento científico, porque precisamos revelar quando é racismo. Então é uma dupla tarefa. (Rodrigo, entrevista pessoal, setembro de 2020)

Esse trecho do discurso de Rodrigo gera um indicador que está diretamente relacionado com a perspectiva decolonial, a qual, como já pontuado, busca demarcar que nenhum conhecimento é universal, mas todos são localizados e provincianos, inclusive os promovidos pela Universidade, que estão enraizados na colonialidade (Connell, 2012). Sendo a noção de contexto muito cara para essa perspectiva, é necessário lembrar do racismo à brasileira como já trazido aqui por Gonzalez (1988), bem como do reconhecimento da colonialidade enquanto fato social total (Balandier,1993), para se realizar uma crítica à Universidade como uma instituição que está inserida numa estrutura racial, fundada com ideais colonizatórios.

Porém, para evitar uma análise fatalista e pensar em um horizonte possível além dos preceitos da modernidade, no qual as universidades resistam a hierarquização de conhecimento, é possível se pensar que os coletivos negros, à exemplo da noção de transmodernidade de Enrique Dussel (2016) se utilizam da disseminação das Negras epistemologias para o enfrentamento desta realidade. No trecho abaixo Rodrigo cita o reconhecimento do negro enquanto um produtor de conhecimento como sendo uma demanda urgente para que exista uma maior humanização desses. 
É necessário desarticular esse saber violento e pautar um saber coletivo que reconheça nossa humanidade. Não se separa corpo e mente da questão do conhecimento. Corporificar e humanizar é nos entender enquanto sujeito e não mais como objeto. É necessário, sobretudo, pautar os nossos conhecimentos enquanto saberes legítimos. (Rodrigo, entrevista pessoal, setembro de 2020)

Uma aposta para realizar esta virada epistemológica são as políticas de ações afirmativas para negros nas Universidades. De acordo com Carvalho (2019) a inclusão dos conhecimentos tradicionais e negras epistemologias nas universidades tende a acontecer de forma gradual e orgânica, visto que as próprias populações ingressantes trarão isso no dia a dia da realidade universitária. Nesse sentido, Carvalho que foi um dos idealizadores da política de cotas epistêmicas nas universidades, vem propondo e implantando uma outra ação afirmativa dentro dos ambientes acadêmicos, o Encontro de Saberes. Intentando que através dessas ações decolonizadoras, aconteça uma subversão da estrutura universitária e uma reconfiguração em sua atuação enquanto instituição colonial (Carvalho, 2019). Em outra frente, observa-se a atuação do Conexões de Saberes, que desde 2004, promove ações que visam a aproximação entre as Universidades e comunidades populares com repercussão no modo de ação das Universidades enquanto locais mais democráticos (Ministério da Educação, 2018)

Não obstante, embora haja, no momento, uma maior sensibilidade para as epistemologias negras na UnB, essas ainda ocupam um espaço minoritário. 0 que indica que somente a presença massiva de alunos negros na graduação ainda não é capaz de gerar modificações radicais na estrutura epistemológica eurocentrada da universidade, e aponta a necessidade do uso da política de afirmações identitárias na inclusão de docentes negros e na ampliação das cotas para todos os programas de pós-graduação.

\section{CONSIDERAÇÕES FINAIS}

Em uma perspectiva contemporânea, o diploma universitário permite a ascensão social, o reconhecimento das qualidades intelectuais e uma melhor posição no mercado de trabalho, e talvez por isso é objeto de desejo de grupos sociais, com intersecção para classe e raça, que historicamente estiveram alijadas das Universidades públicas. Essas, enquanto um projeto colonialista, por estarem preparadas para formação de uma elite branca, permaneceram por décadas sem grandes questionamentos internos de sua lógica segregacionista e eurocêntrica, e também de sua atuação pouco eficiente na solução de problemas internos como as desigualdades sociais e o racismo. 
Após mais de um século do fim da escravidão, pela primeira vez, pessoas negras passaram a ter direito a uma política reparatória. A adoção das políticas de cotas integrou às Universidades públicas, um massivo contingente de estudantes negros, e a UnB, dado o seu protagonismo no debate das ações afirmativas, se situa no centro desse palco.

Necessitando de uma maior quantidade de análises das trajetórias para se complexificar o campo aqui levantado, as trajetórias analisadas demonstram que o ingresso na Universidade, além de ser a realização de um sonho, pode ser também um momento de sofrimento, de rejeição, introjeção do racismo estrutural e auto sabotagem. A ausência de um suporte institucional oficial, os leva a após o ingresso a ter de percorrer, de forma solitária, trajetórias subjetivas dentro das grades curriculares e pelos corredores da UnB.

0 encontro com os coletivos negros se apresenta como um marco na trajetória desses estudantes, onde recebem o acolhimento afetivo, percebem que não estão sós, angariam recursos intelectuais e subjetivos, nomeiam o sofrimento, lutam contra a opressão, se empoderam e se tornam potências individuais e coletivas.

A UnB se apresenta, assim, como um campo em disputa, em que os estudantes negros organizados em coletivos negros se tornam agentes da reestruturação da universidade em benefício de uma sociedade mais igualitária e em compasso com as demandas da sociedade brasileira, que é em sua maior parte negra.

\section{REFERÊNCIAS}

Araújo, Marivânia Conceição; Moreira, Liége Torresan; Felipe, Delton. (2020). Trajetórias Negras na Universidade: resistências, histórias e intelectualidades (1 ed.) UNIEDUSUL.

Balandier, Georges (1993). A noção de situação colonial. Cadernos de Campo (São Paulo 1991), 3(3), 107-131. https://doi.org/10.11606/issn.2316-9133.v3i3p107-131

Ballestrin, Luciana (2013). América Latina e o giro decolonial. Revista brasileira de ciência política, 11, 89-117. https://doi.org/10.1590/S0103-33522013000200004

Bandura, Albert (1997). Autoeficácia: O exercício de controle. Freeman.

Bastos, João Luiz; Barros, Aluisio J. D.; Celeste, Roger Keller; Paradies, Yin \& Faerstein, Eduardo. (2014). Age, class and race discrimination: their interactions and associations with mental health among Brazilian university students. Cadernos de Saúde Pública, 30(1), 175-186. https://doi.org/10.1590/0102-311X00163812

Bernardino-Costa, Joaze; Maldonado-Torres, Nelson \& Grosfoguel, Ramón. (2018). Decolonialidade e pensamento afrodiaspórico. Autêntica.

Boas, Franz (2004). As limitações do método comparativo da antropologia; Raça e progresso. Em Celso Castro (Ed.), Antropologia Cultural (pp. 25-40). Jorge Zahar. 
Carvalho, José Jorge de (2005). Usos e abusos da antropologia em um contexto de tensão racial: o caso das cotas para negros na UnB. Horizontes Antropológicos, 11(23), 237-246. https://dx.doi.org/10.1590/S0104-71832005000100018

Carvalho, José Jorge de. (2011). Inclusão étnica e racial no Brasil: a questão das cotas no ensino superior. $2^{\mathrm{a}}$. Ed. Attar.

Carvalho, José Jorge de (2019). Encontro de saberes e descolonização: para uma refundação étnica, racial e epistêmica das universidades brasileiras. Em BernardinoCosta, Joaze; Maldonado-Torres, Nelson \& Grosfoguel, Ramon (Ed.), Decolonialidade e pensamento afrodiaspórico (pp. 79-106). Autêntica.

Carvalho, José Jorge de; da Silva (Makota Kidoiale), Cássia Cristina; Nolasco de Carvalho, Emílio \& Lima da Costa, Samira. (2020). Sofrimento psíquico na universidade, psicossociologia e Encontro de saberes. Sociedade e Estado, 35(1), 135-162. https://doi.org/10.1590/s0102-6992-202035010007

Carvalho, José Jorge de \& Segato, Rita Laura (2002). Uma proposta de cotas para estudantes negros na Universidade de Brasília, (314). Departamento de Antropologia, Universidade de Brasília.

Castro, Ricardo Dias, \& Mayorga, Cláudia (2018). Classe Média Negra Universitária: por um projeto de sociedade afirmativa. Revista De Estudos E Pesquisas Sobre As Américas, 12(3), 175-203. https://doi.org/10.21057/repamv12n3.2018.29803

Connell, Raewyn. (2012). A iminente revolução na teoria social. Revista Brasileira de Ciências Sociais, 27(80), 09-20. https://doi.org/10.1590/S0102-69092012000300001

Damasceno, Marizete Gouveia \& Zanello, Valeska M. Loyola. (2018). Saúde Mental e Racismo Contra Negros: Produção Bibliográfica Brasileira dos Últimos Quinze Anos. Psicologia: Ciência e Profissão, 38(3), 450-464. https://doi.org/10.1590/1982$\underline{37030003262017}$

Dussel, Enrique (1993). 1492- o encobrimento do outro: a origem do mito da modernidade (Trad. Jaime A. Clasen). Vozes.

Dussel, Enrique. (2016). Transmodernidade e interculturalidade: interpretação a partir da filosofia da libertação. Sociedade e Estado, 31(1), 51-73.

https://doi.org/10.1590/S0102-69922016000100004

Fanon, Frantz (1952/2008). Pele negra, máscaras brancas (Tradução: Renato de Silveira). EDUFBA.

Fontoura, Loiraci Firmo da (2019). Ações afirmativas e cotas: um estudo de revisão bibliográfica. Universidade Federal do Pampa.

Freyre, Gilberto (2003). Casa-grande \& senzala. Global Editora e Distribuidora Ltda.

Gonzalez, Lélia (1988). A categoria político-cultural de amefricanidade. Tempo brasileiro, 92(93), 69-82.

González Rey, Fernando Luis \& Mitjáns Martínez, Albertina (2017). Subjetividade: teoria, epistemologia e método. Alínea.

Grosfoguel, Ramón (2016). A estrutura do conhecimento nas universidades ocidentalizadas: racismo/sexismo epistêmico e os quatro genocídios/epistemicídios do longo século XVI. Sociedade e Estado, 31(1), 25-49. https://doi.org/10.1590/S0102$\underline{69922016000100003}$ 
Guimarães, Antônio Sérgio (2003). Como trabalhar com “raça” em sociologia. Educação e Pesquisa, 29(1), 93-107. https:// doi.org/10.1590/S1517-97022003000100008

Guimarães, Antônio Sérgio (2016). Formações nacionais de classe e raça. Tempo Social, 28(2), 161-182. https://doi.org/10.11606/0103-2070.ts.2016.109752

Hall, Stuart (2006). A identidade cultural na pós-modernidade (Tradução Tomaz Tadeu da Silva, 11. Ed.). DP\&A

Laraia, Roque de Barros (2005). Da Ciência Biológica à Social: a trajetória da Antropologia no século XX. Habitus, 3(2), 321-345.

http://dx.doi.org/10.18224/hab.v3.2.2005.321-345

Lima, Stephanie (2020). “A gente não é só negro!”: interseccionalidade, experiência e afetos na ação política de negros universitários. Tese de doutorado inédita, Universidade Estadual de Campinas.

http://repositorio.unicamp.br/jspui/handle/REPOSIP/346919

Lopes, Nei (2011). Bantos, Malês e Identidade Negra. Autêntica.

Mayorga, Cláudia, \& de Souza, Luciana Maria (2012). Ação afirmativa na universidade: a permanência em foco. Revista psicologia política, 12(24), 263-281.

Mbembe, Achille (2013). África Insubmissa: Cristianismo, poder e Estado na sociedade pós-colonial. Edições Pedago.

Mbembe, Achille (2014). A Crítica da Razão Negra. Antígona.

Mignolo, Walter (2003). Histórias locais-projetos globais: colonialidade, saberes subalternos e pensamento liminar. Ed. UFMG.

Ministério da Educação (2018). Conexões de Saberes. MEC Brasil. Recuperado de http://portal.mec.gov.br/conexoes-de-saberes

Nascimento, Abdias (1978/2016). O genocídio do negro brasileiro: Processo de um racismo mascarado. Editora Perspectiva

Nascimento, Abdias (1980/2020). O quilombismo. Editora Perspectiva.

Nogueira, Oracy (2007). Preconceito racial de marca e preconceito racial de origem: sugestão de um quadro de referência para a interpretação do material sobre relações raciais no Brasil. Tempo social, 19(1), 287-308.

Oliveira, lara Andrade de; Maia, Luciana Maria \& Lima, Tiago Jessé (2020). Cotas Raciais na Universidade: Uma Revisão Integrativa da Psicologia Brasileira. Revista Subjetividades, 20. https://doi.org/10.5020/23590777.rs.v20iEsp1.e9337

Pereira, Bruna Cristina Jaquetto (2019). Dengos e zangas das mulheres-moringa: vivências afetivo-sexuais de mulheres negras. Tese de doutorado inédita, Universidade de Brasília. https: / / repositorio.unb.br/handle/10482/36124

Pierson, Donald (1971). Brancos e pretos na Bahia. Editora Nacional.

Prado, Marco Aurélio (2002). Da mobilidade social à constituição da identidade política: reflexões em torno dos aspectos psicossociais das ações coletivas. Psicologia em revista, 8(11), 59-71.

Quijano, Aníbal (1992). Colonialidad y Modernidad-racionalidad. Em Bonillo, Heraclio (Ed). Los conquistados. Tercer Mundo Ediciones; FLACSO. 
Rivera, Silvia Cusicanqui (2010). Ch'ixinakax utxiwa. Una reflexión sobre prácticas y discursos descolonizadores. Tinta Limón.

Santos, Alessandro de Oliveira dos, Schucman, Lia Vainer, \& Martins, Hildeberto Vieira. (2012). Breve histórico do pensamento psicológico brasileiro sobre relações étnico-raciais. Psicologia: Ciência e Profissão, 32, 166-175. https://dx.doi.org/10.1590/S1414-98932012000500012

Schucman, Lia Vainer (2012). Entre o encardido, o branco e o branquíssimo: raça, hierarquia e poder na construção da branquitude paulistana. Tese de Doutorado inédita, Universidade de São Paulo. https://www.teses.usp.br/teses/disponiveis/47/47134/tde-21052012-154521/ptbr.php

Schucman, Lia Vainer, \& Gonçalves, Mônica Mendes. (2020). Raça e subjetividade: do campo social ao clínico. Arquivos Brasileiros de Psicologia, 72, 109-123. http: / / pepsic.bvsalud.org/scielo.php?script=sci_abstract\&pid=S180952672020000300009

Schucman, Lia Vainer; Mandelbaum, Belinda \& Fachim, Felipe Luis (2017). Minha mãe pintou meu pai de branco: afetos e negação da raça em famílias interraciais. Revista de Ciências Humanas, 51(2), 439-455. https:// doi.org/10.5007/21784582.2017v51n2p439

Souza, Neusa Santos (1983). Tornar-se negro: as vicissitudes da identidade do negro brasileiro em ascensão social. Edições Graal.

Tavares, Jeane Saskya Campos \& Kuratani, Sayuri Miranda de Andrade. (2019). Manejo Clínico das Repercussões do Racismo entre Mulheres que se "Tornaram Negras". Psicologia: Ciência e Profissão, 39. https://doi.org/10.1590/1982-3703003184764

Tempesta, Giovana Acácia; Araújo, João Paulo Siqueira \& Loiola, Diego Rodrigues (2019) Revisitando conceitos antropológicos clássicos em um museu imaginado. Cadernos de Campo (São Paulo 1991), 28(2), 47-66. http://www.revistas.usp.br/cadernosdecampo/article/view/155518

Universidade de Brasília (2019). Anuário Estatístico da UnB: 2019: período 2014 a 2018. Decanato de Planejamento, Orçamento e Avaliação Institucional. http://dpo.unb.br/images/phocadownload/unbemnumeros/anuarioestatistico/Anuar ioEstatistico2019.pdf

Wallerstein, Immanuel (2007). O universalismo europeu: o discurso do poder. Boitempo.

Zanello, Valeska (2018). Saúde Mental, gênero e dispositivos: Cultura e processos de subjetivação. Appris. 


\section{JoÃo PAULO SIQUEIRA}

Graduando em Psicologia pela Universidade de Brasília (UnB), bolsista CNPq de Iniciação Científica na área de Sociologia. Tem interesse nos estudos sobre relações étnico-raciais na interface com saúde mental.

joaop.307@gmail.com

https://orcid.org/0000-0002-6154-1324

\section{RODRIGO MACIEL RAMOS}

Psicólogo, Mestre em Psicologia pelo UniCEUB-DF e, atualmente, doutorando no Programa de Pós Graduação em Psicologia Social, do Trabalho e das Organizações (PPG-PSTO) da Universidade de Brasília. Tem experiência na produção de conhecimento afrocentrada, com interesse especial nos cuidados em saúde mental das culturas do candomblé e da umbanda.

magorodrigo2@gmail.com

https://orcid.org/0000-0001-9770-5901

\section{FORMATO DE CITACIÓN}

Siqueira, João Paulo \& Ramos, Rodrigo Maciel (2021). As (re)configurações subjetivas e identitárias de negros na Universidade: Fricções epistêmicas e aquilombamento acadêmico. Quaderns de Psicologia, 23(3), e1766.

https://doi.org/10.5565/rev/qpsicologia.1766

HISTORIA EDITORIAL

Recibido: 30-01-2021

$1^{\text {a }}$ revisión: 28-04-2021

Aceptado: $30-05-2021$

Publicado: 25-01-2022 